\title{
The "Forced to help" study: study design, methods and epidemiological data Ingemar Engström
}

\author{
Address: Örebro University, Psychiatric Research Center, P.O. Box 1613, 70116 Örebro, Sweden \\ from WPA Thematic Conference. Coercive Treatment in Psychiatry: A Comprehensive Review \\ Dresden, Germany. 6-8 June 2007 \\ Published: 19 December 2007 \\ BMC Psychiatry 2007, 7(Suppl I):SI04 doi:I0.II86/I47I-244X-7-SI-SI04
}

This abstract is available from: http://www.biomedcentral.com/I47I-244X/7/SI/SI04

(C) 2007 Engström; licensee BioMed Central Ltd.

\section{Background}

The aim of the study was to examine coercive treatment in Swedish child and adolescent psychiatry from different scientific perspectives. The study was done in a multidisciplinary group comprised of researchers and $\mathrm{PhD}$-students from child and adolescent psychiatry, law, philosophy, education and sociology. In this presentation, the design of the study will be presented and also some preliminary epidemiological data.

\section{Methods}

Epidemiological data from the period 2000 - 2004 was collected from all clinics in Sweden. Hospital records concerning all involuntarily admitted persons less than 18 years of age during one year were also collected from all clinics in Sweden.

\section{Results}

We found a tendency towards more coercive care during recent years. At least 150 children and adolescents were involuntarily admitted annually. The variation between counties was considerable. In some counties, adolescents on coercive treatment were treated together with adults. Girls were involuntarily admitted twice as often as boys. The most frequent diagnoses were psychosis, anorexia nervosa, self-destructive behavior and drug abuse.

\section{Conclusion}

Coercive treatment seems to be more frequent in recent years, but the variation is large between different counties. Contrary to adults, girls are more frequently treated involuntarily than boys. Further analysis of data is necessary to get a more comprehensive picture of the reasons for coercion of under aged persons. 